\title{
A -Synthesis Approach to Robust Control of a Wind Turbine
}

\section{Mirzaei, Mahmood; Niemann, Hans Henrik; Poulsen, Niels Kjølstad}

Published in:

2011 50th IEEE Conference on Decision and Control and European Control Conference (CDC-ECC)

Link to article, DOI:

10.1109/CDC.2011.6161124

Publication date:

2011

Link back to DTU Orbit

Citation (APA):

Mirzaei, M., Niemann, H. H., \& Poulsen, N. K. (2011). A -Synthesis Approach to Robust Control of a Wind

Turbine. In 2011 50th IEEE Conference on Decision and Control and European Control Conference (CDC-ECC) (pp. 645-650). IEEE. https://doi.org/10.1109/CDC.2011.6161124

\section{General rights}

Copyright and moral rights for the publications made accessible in the public portal are retained by the authors and/or other copyright owners and it is a condition of accessing publications that users recognise and abide by the legal requirements associated with these rights.

- Users may download and print one copy of any publication from the public portal for the purpose of private study or research.

- You may not further distribute the material or use it for any profit-making activity or commercial gain

- You may freely distribute the URL identifying the publication in the public portal

If you believe that this document breaches copyright please contact us providing details, and we will remove access to the work immediately and investigate your claim 


\title{
A $\mu$-Synthesis Approach to Robust Control of a Wind Turbine
}

\author{
Mahmood Mirzaei, Hans Henrik Niemann and Niels Kjølstad Poulsen
}

\begin{abstract}
The problem of robust control of a wind turbine is considered in this paper. A set of controllers are designed based on a 2 degrees of freedom linearized model of a wind turbine. An extended Kalman filter is used to estimate effective wind speed and the estimated wind speed is used to find the operating point of the wind turbine. Due to imprecise wind speed estimation, uncertainty in the obtained linear model is considered. Uncertainties in the drivetrain stiffness and damping parameters are also considered as these values are lumped parameters of a distributed system and therefore they include inherent uncertainties. We include these uncertainties as parametric uncertainties in the model and design robust controllers using the $D K$-iteration method. Based on estimated wind speed a pair of controllers are chosen and convex combination of their outputs is applied to the plant. The resulting set of controllers is applied on a full complexity simulation model and simulations are performed for stochastic wind speed according to relevant IEC standard.
\end{abstract}

\section{INTRODUCTION}

In the recent decades there has been an increasing interest in green energies of which wind energy is one of the most important ones. Wind turbines are the most common wind energy conversion systems (WECS) and are hoped to be able to compete with fossil fuel power plants on the energy price in near future. However this demands better technology to reduce electricity production price. Control can play an essential part in this context because control methods on one hand can decrease the cost of energy by keeping the turbine close to its maximum efficiency. On the other hand reduce structural fatigue and therefore increase lifetime of the wind turbine. There are several methods for wind turbine control ranging from classical control methods [1] which are the most used methods in real applications to advanced control methods which have been the focus of research recently [2]. Gain scheduling [3], adaptive control [4], MIMO methods [5], nonlinear control [6], robust control [7], model predictive control [8], $D K$-iteration [9] just to mention a few. Advanced control methods are thought to be the future of wind turbine control as they can employ new generations of sensors on wind turbines (e.g. LIDAR [10]), new generation of actuators (e.g. trailing edge flaps [11]) and also conveniently treat the turbine as a MIMO system. The last feature seems to become

This work is supported by the CASED Project funded by grant DSF-09063197 of the Danish Council for Strategic Research.

M. Mirzaei is with department of Informatics and Mathematical Modeling, Technical University of Denmark, 2800 Kongens Lyngby, Denmark mmireimm.dtu.dk

H. H. Niemann is with department of Electrical Engineering, Technical University of Denmark, 2800 Kongens Lyngby, Denmark hhn@elektro.dtu.dk

N. K. Poulsen is with department of Informatics and Mathematical Modeling, Technical University of Denmark, 2800 Kongens Lyngby, Denmark nkp@imm.dtu.dk more important than before as wind turbines become bigger and more flexible which make decoupling different modes and designing controller for each mode more difficult. The wind turbine in this paper is treated as a MIMO system with pitch $\left(\theta_{i n}\right)$ and generator reaction torque $\left(Q_{i n}\right)$ as inputs and rotor rotational speed $\left(\omega_{r}\right)$, generator rotational speed $\left(\omega_{g}\right)$ and generated power $\left(P_{e}\right)$ as outputs. Parametric uncertainties considered and $D K$-iteration method [12] is used to solve the control problem. $D K$-iteration is a method that takes structured uncertainty into account in order to reduce conservativeness of the $H_{\infty}$ procedure. A set of controllers each of which responsible for a specific region of the operation range are designed. We use wind speed estimation to choose pair of controllers and also to calculate convex combination of controller pair outputs to apply to the plant. This paper is organized as follows: In section II modeling of the wind turbine including modeling for wind speed estimation, linearization and uncertainty modeling is addressed. In section III controller design is explained. Finally in section IV simulation results are presented.

\section{Modeling OF THE Wind TuRbine}

For modeling purposes, the whole wind turbine can be divided into 4 subsystems: Structural subsystem, aerodynamics subsystem, electrical subsystem and actuator subsystem. The dominant dynamics of the wind turbine come from its structure which includes drivetrain, tower and blades. Several degrees of freedom could be considered to model the structure, but for control design mostly just a few important degrees of freedom are considered. In this work we only consider two degrees of freedom, namely the rotational degree of freedom (DOF) and drivetrain torsion. The aerodynamics subsystem gets effective wind speed $\left(v_{e}\right)$, pitch angle $(\theta)$ and rotational speed of the rotor $\left(\omega_{r}\right)$ and returns aerodynamic

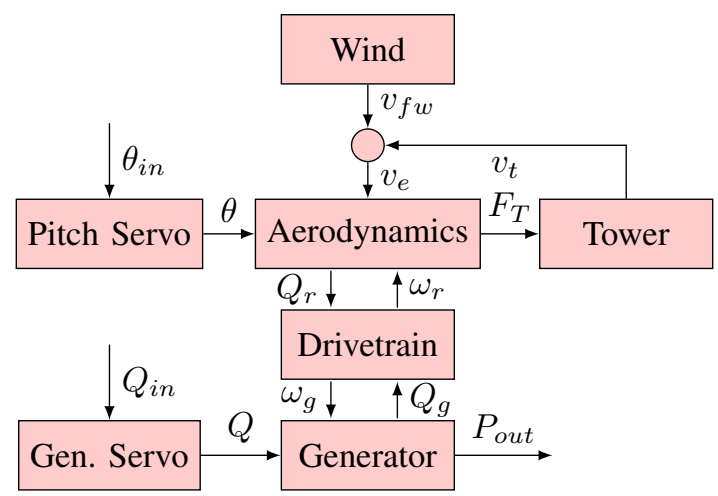

Fig. 1: Wind turbine subsystems 
torque $\left(Q_{r}\right)$ and thrust $\left(Q_{T}\right)$. The aerodynamic subsystem is responsible for the nonlinearity in the wind turbine model. More details are presented in section II-B.

\section{A. Modeling for Estimation}

Wind can be modeled as a complicated nonlinear stochastic process, however for practical purposes it could be approximated by a linear model [13]. In this model the wind has two elements, mean value term $\left(v_{m}\right)$ and turbulent term $\left(v_{t}\right)$ :

$$
v_{e}=v_{m}+v_{t}
$$

The turbulent term is modeled by the following transfer function:

$$
v_{t}=\frac{k\left(v_{m}\right)}{\left(p_{1}\left(v_{m}\right) s+1\right)\left(p_{2}\left(v_{m}\right) s+1\right)} e ; \quad e \in N(0,1)
$$

And in the state space form:

$$
\begin{aligned}
\left(\begin{array}{c}
\dot{v}_{t} \\
\ddot{v}_{t}
\end{array}\right)= & \left(\begin{array}{cc}
0 & 1 \\
-\frac{1}{p_{1}\left(v_{m}\right) p_{2}\left(v_{m}\right)} & -\frac{p_{1}\left(v_{m}\right)+p_{2}\left(v_{m}\right)}{p_{1}\left(v_{m}\right) p_{2}\left(v_{m}\right)}
\end{array}\right) \\
& \left(\begin{array}{c}
v_{t} \\
\dot{v}_{t}
\end{array}\right)+\left(\begin{array}{c}
0 \\
\frac{k\left(v_{m}\right)}{p_{1}\left(v_{m}\right) p_{2}\left(v_{m}\right)}
\end{array}\right) e
\end{aligned}
$$

This is a second order approximation of the wind power spectrum [13]. For wind speed estimation, a one DOF nonlinear model of the wind turbine is augmented with the wind model given above. An extended Kalman filter uses this model to estimate the effective wind speed. This wind speed is used to find the operating point of the wind turbine and to calculate appropriate control signals.

\section{B. Nonlinear Model}

Blade element momentum (BEM) theory [14] is used to calculate aerodynamic torque and thrust on the wind turbine. BEM theory explains how torque and thrust are related to wind speed, blade pitch angle and rotational speed of the rotor with the following formulas:

$$
\begin{aligned}
Q_{r} & =\frac{1}{2} \frac{1}{\omega_{r}} \rho \pi R^{2} v_{e}^{3} C_{P}\left(\theta, \omega, v_{e}\right) \\
Q_{t} & =\frac{1}{2} \rho \pi R^{2} v_{e}^{2} C_{T}\left(\theta, \omega, v_{e}\right)
\end{aligned}
$$

In which $Q_{r}$ and $Q_{t}$ are aerodynamic torque and thrust, $\rho$ is air density, $\omega_{r}$ is rotor rotational speed, $v_{e}$ is effective wind speed, $C_{P}$ is the power coefficient and $C_{T}$ is the thrust force coefficient. Absolute angular position of the rotor and generator are of no interest to us, therefore we use the drivetrain torsion $\psi=\theta_{r}-\theta_{g}$ instead. Having aerodynamic torque the whole system equation with 2 degrees of freedom becomes:

$$
\begin{aligned}
J_{r} \dot{\omega}_{r} & =Q_{r}-c\left(\omega_{r}-\frac{\omega_{g}}{N_{g}}\right)-k \psi \\
\left(N_{g} J_{g}\right) \dot{\omega}_{g} & =c\left(\omega_{r}-\frac{\omega_{g}}{N_{g}}\right)+k \psi-N_{g} Q_{g} \\
P_{e} & =Q_{g} \omega_{g}
\end{aligned}
$$

In which $J_{r}$ and $J_{g}$ are rotor and generator moments of inertia, $\psi$ is the drivetrain torsion, $c$ and $k$ are the drivetrain damping and stiffness factors respectively lumped in the low speed side of the shaft and $P_{e}$ is the generated power. For numerical values of these parameters and other parameters given in this paper, we refer the reader to [15]. These equations give a nonlinear model. However we need to linearize the nonlinear model of the system. This could be easily achieved using Taylor expansions around the operating points:

$$
\begin{aligned}
& \Delta Q_{r}=a \Delta \omega_{r}+b_{1} \Delta \theta+b_{2} \Delta v_{e} \\
& \Delta P_{e}=Q_{g}^{*} \Delta \omega_{g}+\omega_{g}^{*} \Delta Q_{g}
\end{aligned}
$$

$Q_{g}^{*}$ and $\omega_{g}^{*}$ are the nominal values of torque and generator speed. For the sake of simplicity in notations we use variables without $\Delta$ from now on.

\section{Uncertain model}

As it was mentioned, for control design we need to have a linear model of the system and the following model of the wind turbine is used:

$$
\left(\begin{array}{c}
\dot{x} \\
y_{\Delta} \\
y
\end{array}\right)=\left(\begin{array}{c|cc}
A & B_{1} & B_{2} \\
\hline C_{1} & D_{11} & D_{12} \\
C_{2} & D_{21} & D_{22}
\end{array}\right)\left(\begin{array}{c}
x \\
u_{\Delta} \\
u
\end{array}\right)
$$

In which states, inputs and outputs are:

$$
\begin{aligned}
& x=\left(\begin{array}{lllllll}
\omega_{r} & \omega_{g} & \psi & \theta & Q_{g} & v_{e} & \dot{v}_{e}
\end{array}\right)^{T} \\
& u=\left(\begin{array}{ll}
\theta_{\text {in }} & Q_{\text {in }}
\end{array}\right)^{T} \\
& y=\left(\begin{array}{lll}
\omega_{r} & \omega_{g} & P_{e}
\end{array}\right)^{T}
\end{aligned}
$$

$\omega_{r}$ is rotational speed of the rotor, $\omega_{g}$ is rotational speed of the generator, $\psi$ is drivetrain deflection, $\theta$ pitch of the blade, $Q_{g}$ is the generator reaction torque, $v_{e}$ and $\dot{v}_{e}$ are wind model states, $\theta_{i n}$ is the reference value for pitch actuatorm, $Q_{i n}$ is the reference value for the generator torque actuator and $P_{e}$ is the electrical power. Having all the equations, system equations become:

$$
\begin{aligned}
\dot{\omega}_{r} & =\frac{a-c}{J_{r}} \omega_{r}+\frac{c}{J_{r}} \omega_{g}-\frac{k}{J_{r}} \psi+b_{1} \theta+b_{2} v_{e} \\
\dot{\omega}_{g} & =\frac{c}{N_{g} J_{g}} \omega_{r}-\frac{c}{N_{g}^{2} J_{g}} \omega_{g}+\frac{k}{N_{g} J_{g}} \psi-\frac{Q_{g}}{J_{g}} \\
\dot{\psi} & =\omega_{r}-\frac{\omega_{g}}{N_{g}} \\
\dot{\theta} & =-\frac{1}{\tau_{\theta}} \theta+\frac{1}{\tau_{\theta}} \theta_{i n} \quad \dot{Q}_{g}=-\frac{1}{\tau_{g}} Q_{g}+\frac{1}{\tau_{g}} Q_{i n} \\
P_{e} & =Q_{g_{0}} \omega_{g}+\omega_{g_{0}} Q_{g} \\
\ddot{v}_{e} & =-\frac{1}{p_{1} p_{2}} v_{e}-\frac{p_{1}+p_{2}}{p_{1} p_{2}} \dot{v}_{e}+\frac{k}{p_{1} p_{2}} e
\end{aligned}
$$

$\tau_{\theta}$ and $\tau_{g}$ are time constants of the first order actuator models (see equ. 10). Uncertainties for the parameters of the equations 7-8 are:

$$
\begin{aligned}
a & =\bar{a}\left(1+p_{a} \delta_{a}\right) & & \text { Linearized model } \\
b_{1} & =\bar{b}_{1}\left(1+p_{b_{1}} \delta_{b_{1}}\right) & & \text { Linearized model } \\
k & =\bar{k}\left(1+p_{k} \delta_{k}\right) & & \text { Drivetrain stiffness } \\
c & =\bar{c}\left(1+p_{c} \delta_{c}\right) & & \text { Drivetrain damping }
\end{aligned}
$$




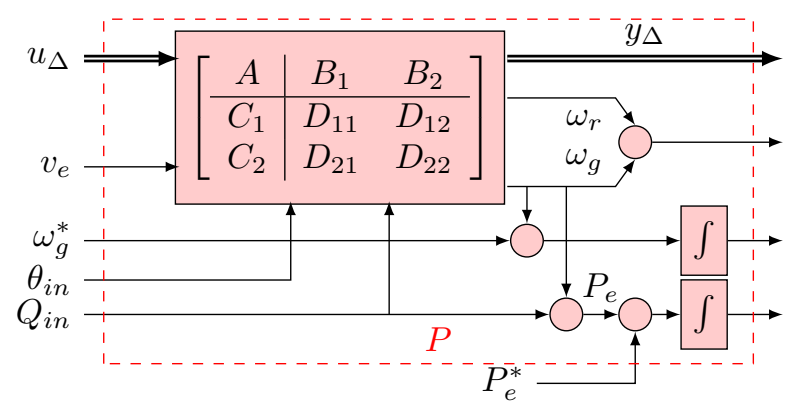

Fig. 2: System interconnections

In which:

$$
\left|\delta_{a}\right| \leq 1, \quad\left|\delta_{b_{1}}\right| \leq 1, \quad\left|\delta_{k}\right| \leq 1, \quad\left|\delta_{c}\right| \leq 1
$$

And $\bar{a}, \bar{b}_{1}, \bar{k}$ and $\bar{c}$ are the nominal values and $p_{a}, p_{b_{1}}, p_{k}$ and $p_{c}$ represent the relative perturbations. Uncertainty in the linearized model could be a result of approximate $C_{P}$ curve calculations, wrong wind speed estimation which results in picking the wrong operating point or aerodynamic changes due to blade flexibility or ice coatings on the blades. Using the equation 13 to represent uncertainties, the uncertainty matrix $(\Delta)$ becomes a diagonal matrix which connects $y_{\Delta}$ and $u_{\Delta}$ :

$$
\begin{aligned}
& u_{\Delta}=\operatorname{diag}\left(\delta_{a}, \delta_{b_{1}}, \delta_{k}, \delta_{c}\right) y_{\Delta} \\
& y_{\Delta}=\left(\begin{array}{llll}
y_{a} & y_{b_{1}} & y_{k} & y_{c}
\end{array}\right)^{T} \\
& u_{\Delta}=\left(\begin{array}{llll}
u_{a} & u_{b_{1}} & u_{k} & u_{c}
\end{array}\right)^{T}
\end{aligned}
$$

\section{Simulation Model}

The FAST (Fatigue, Aerodynamics, Structures, and Turbulence) code [16] is used as the simulation model and the $5 \mathrm{MW}$ reference wind turbine is used as the plant [15]. In the simulation model 10 degrees of freedom are enabled which are: generator, drivetrain torsion, 1 st and 2 nd tower fore-aft, 1 st and 2nd tower side-side, 1st and 2nd blade flapwise, 1st blade edgewise degrees of freedom.

\section{Controller Design}

\section{A. Control Objectives}

The most basic control objective of a wind turbine is to maximize captured power and prolong life time of the wind turbine. The second objective is achieved by minimizing the fatigue loads. Generally maximizing power capture is considered in the partial load and minimizing fatigue loads is mainly considered above rated. As we are operating in the full load region in this work, we have considered the second objective. Control objectives are formulated in the form of weighting functions on input disturbances $(d)$ and exogenous outputs $(z)$. In order to avoid high frequency activity of the actuators, we have put high pass filter on control signals to penalize high frequency actions. Also we have setup low pass filters to penalize only low frequency of some of the system outputs as their high frequency dynamics are outside
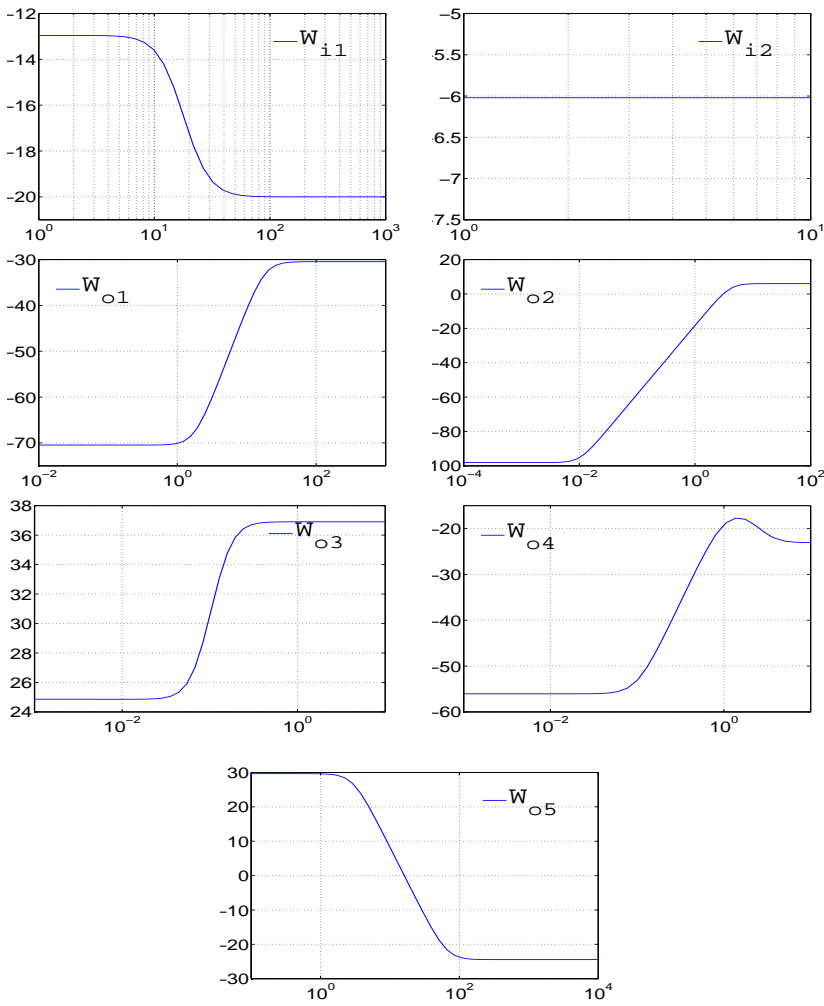

Fig. 3: Bode plots for performance specifications(y-axis is in $\mathrm{dB}$ and $\mathrm{x}$-axis is in $\mathrm{rad} / \mathrm{s}$ )

of our actuator bandwidth and we can not control them. For regulating power and rotational speed, $\int P_{e}-P_{e}^{*}$ and $\int \omega_{g}-\omega_{g}^{*}$ and for minimizing fatigue loads on the drivetrain $\omega_{g}-N_{g} \omega_{r}$ are penalized.

\section{B. Nominal Performance Problem}

1) Theory: $H_{\infty}$ control theory [12] is used to solve the nominal performance problem. In this problem the $\Delta$ matrix is considered zero (no perturbation) and the following problem is solved:

$$
K(s)=\arg \min _{K \in \mathcal{K}}\left\|W_{o} F_{l}(P, K) W_{i}(j \omega)\right\|_{\mathcal{H}_{\infty}}
$$

In which $F_{l}(P, K)$ is the lower LFT of plant $P$ (figure 2) and controller $K . W_{i}$ and $W_{o}$ are frequency dependent weighting matrices on disturbances and exogenous outputs respectively of the form:

$$
\begin{aligned}
& W_{o}=\operatorname{diag}\left(W_{o 1}, \ldots, W_{o 5}\right) \\
& W_{i}=\operatorname{diag}\left(W_{i 1}, W_{i 2}\right)
\end{aligned}
$$

Bode plots of the weighting functions are given in the figure 3 . Input disturbances $(d)$ and exogenous outputs $(z)$ are (see 
figure 2)

$$
\begin{aligned}
& d=\left(\begin{array}{c}
v_{e} \\
\omega_{g}^{*}
\end{array}\right) \quad \begin{array}{l}
\text { Wind Speed } \\
\text { Rotor rotation reference }
\end{array} \\
& z=\left(\begin{array}{c}
\theta_{i n} \\
Q_{i n} \\
\omega_{r}^{*}-\frac{\omega_{g}}{N_{g}} \\
\int \omega_{g}^{*}-\omega_{g} \\
\int P_{e}^{*}-P_{e}
\end{array}\right) \begin{array}{l}
\text { Pitch reference } \\
\text { Deflection of the drivetral of rotational speed error } \\
\text { Integral of generated power error }
\end{array}
\end{aligned}
$$

The optimization problem suggests that we are trying to find a controller in the set of stabilizing controllers that minimizes $H_{\infty}$-norm of weighted sensitivity function. This means we try to minimize the peak frequency of $W_{o} S W_{i}(j \omega)$. The resulting controller guarantees nominal performance if:

$$
\left\|W_{o} F_{l}(P, K) W_{i}(j \omega)\right\|_{\mathcal{H}_{\infty}}<1
$$

2) Implementation: The robust control toolbox [17] is used to solve the above problem. The controller is found trying to minimize transfer function from the disturbances (vector $d$ ) to the exogenous outputs (vector $z$ ). The controller that is designed here is used in Simulink on the full complexity FAST model of the 5MW reference wind turbine [15] (explained in section II-D) .

\section{Robust Performance Problem}

1) Theory: Robust performance means that the performance objective is satisfied for all possible plants in the uncertainty set. The robust performance condition can be cast into a robust stability problem with an additional perturbation block that defines $H_{\infty}$ performance specifications [12]. The structured singular value $\mu$ is a very powerful tool for the analysis of robust performance with a given controller. However this is an analysis tool, in order to design a controller, we need a synthesis tool. A scaled version of the upper bound of $\mu$ is used for controller synthesis. The problem is formulated in the following form:

$$
\mu_{\Delta}(N(K)) \leq \min _{D \in \mathcal{D}} \sigma\left(D N(K) D^{-1}\right)
$$

Now, the synthesis problem can be cast into the following optimization problem in which one tries to to find a controller that minimizes the peak value over frequency of this upper bound:

$$
\min _{K \in \mathcal{K}}\left(\min _{D \in \mathcal{D}}\left\|D N(K) D^{-1}\right\|_{\infty}\right)
$$

This problem is solved by an iterative approach called $D K$-iteration. For detailed explanations on the method and notations the reader is referred to [12].

2) Implementation: We have used the $D K$-Iteration algorithm of the $\mu$-Synthesis toolbox [18] to design controllers. Figure 4 shows robust performance problem setup. $W_{\Delta}$ is used to scale the $\Delta$ matrix. We have taken uncertainty of $10 \%$ of the nominal values for the drivetrain stiffness and damping coefficients and $20 \%$ for the linearization parameters therefore the weighting matrix becomes:

$$
W_{\Delta}=\operatorname{diag}(0.2,0.2,0.1,0.1)
$$

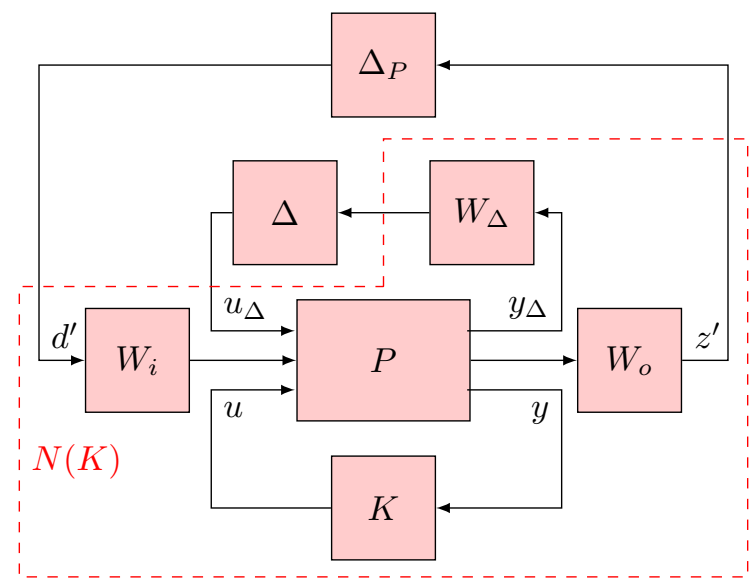

Fig. 4: System setup for robust performance problem

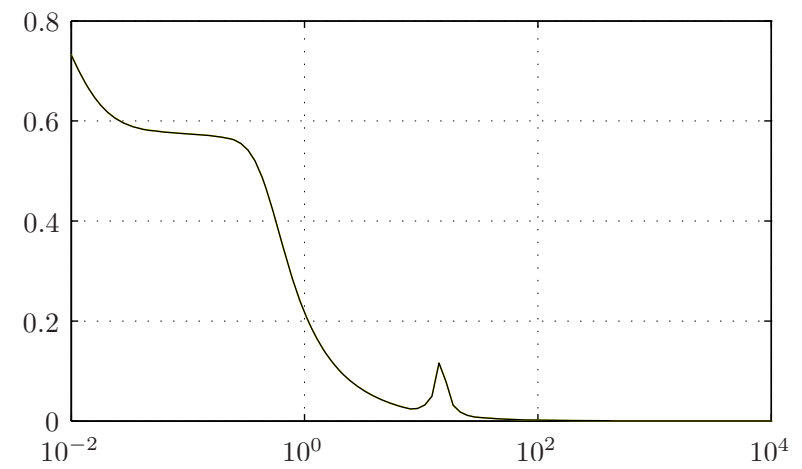

Fig. 5: Mixed $\mu$ for one of the controllers $\left(v_{e}=16 \mathrm{~m} / \mathrm{s}\right)$

$\Delta_{P}$ scaled by $W_{i}$ and $W_{o}$ matrices defines performance of the system in the form of a complex perturbation matrix. The resulting mixed- $\mu$ for one of the controllers is given in figure 5 and the iteration summery in table I. Order of the resulting controllers (only one is shown in the table I) are between 21 to 27 , and since high order controllers are problematic in the implementation phase, we have used balanced order reduction to reduce order of all the controllers to 15 .

\section{Control Signal Calculation}

Wind turbines are highly nonlinear plants and one single controller which is designed based on a linear model of an operating point is not able to handle the whole operating region unless we give away too much performance in favor of robustness of the controller. One way to avoid this problem is to design a set of controllers each of which is responsible for a specific range of operation. We employ the estimated wind speed to choose a pair of controllers that are closest to the operating point and then use a convex combination of their outputs to calculate control signals to the plant. The

\begin{tabular}{lccc} 
Iteration number & 1 & 2 & 3 \\
\hline Controller Order & 21 & 23 & 25 \\
$\gamma$ Acheived & 9682006.84 & 24.327 & 4.726 \\
Peak $\mu$-Value & 1355.81 & 0.527 & 0.475
\end{tabular}

TABLE I: $D K$-iteration summery for one of the controllers 


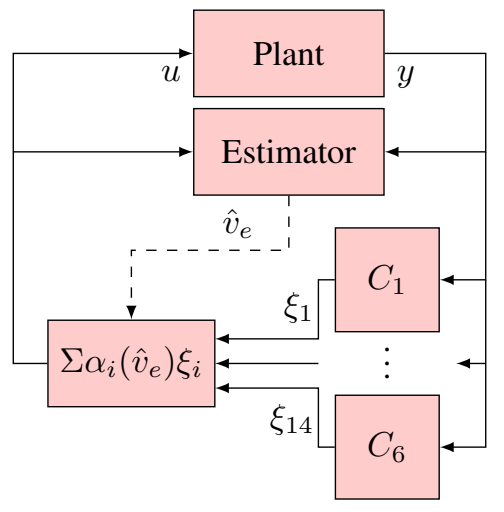

Fig. 6: Control configuration for the whole region

following formula is used to calculate the control signal:

$$
\begin{aligned}
& \alpha\left(\hat{v}_{e}\right)=\hat{v}_{e}-v_{k} \quad v_{k} \leq \hat{v}_{e}<v_{k+1} \\
& u=\left(1-\alpha\left(\hat{v}_{e}\right)\right) \xi_{k}+\alpha\left(\hat{v}_{e}\right) \xi_{k+1}
\end{aligned}
$$

$\hat{v}_{e}$ is the estimated wind speed, $v_{k} \in \mathbb{V}$ which:

$$
\mathbb{V}=\{12,13, \ldots, 25\}
$$

And $\xi_{k}$ 's are defined as:

$$
\begin{array}{llll}
\xi_{1,2} & =C_{1} & \xi_{3,4} & =C_{2} \\
\xi_{5,6} & =C_{3} & \xi_{7,8,9} & =C_{4} \\
\xi_{10,11,12} & =C_{5} & \xi_{13,14} & =C_{6}
\end{array}
$$

In which $C_{i}$ 's are controllers outputs. In order to reduce the number of controllers, controllers are designed only for wind speeds of $12,14,16,18,21,24(\mathrm{~m} / \mathrm{s})$. As the aerodynamic gains do not change much in the high wind speeds and one controller can cover a bigger range of operating points, we have made the control grid larger in that area. Figure 6 shows the diagram of control signal calculation. In this figure, the block $\Sigma$ gets control signals from all the controllers and based on the estimated wind speed $\hat{v}_{e}$ calculates control signal $u$. Figure 12 shows the controller selection sequence $\left(u_{k}\right)$.

\section{Simulation Results}

In this section simulation results for the obtained controllers are presented. The controllers are implemented in MATLAB and are tested on the full complexity FAST model of the reference wind turbine [15]. Kaimal model is used as the turbulence model and in order to stay in the above rated region, a realization of turbulent wind speed from category $C$ of the IEC turbulence categories with $18 \mathrm{~m} / \mathrm{s}$ as the mean wind speed is used.

\section{A. Wind Speed Estimation}

An extended Kalman filter is used to estimate the wind speed. Figure 7 shows the effective and the estimated wind speeds.

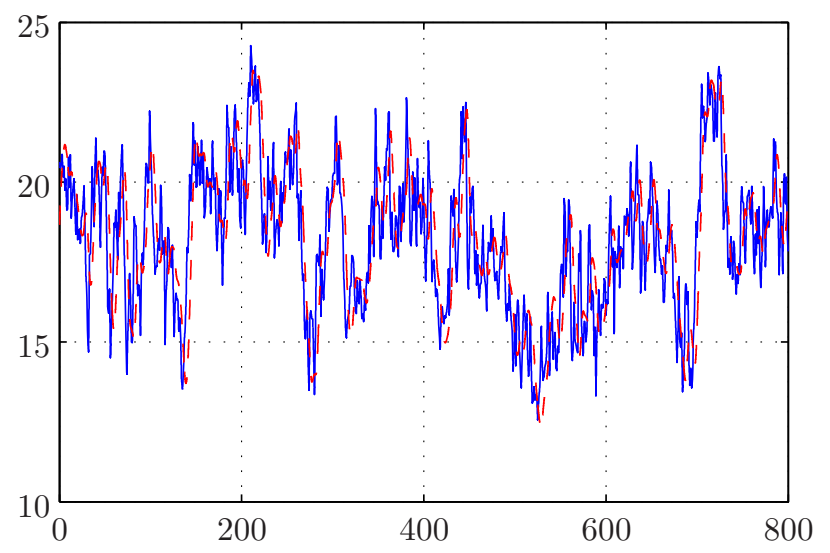

Fig. 7: Wind speed (blue-solid), Estimated wind speed (reddashed) $(\mathrm{m} / \mathrm{s})$

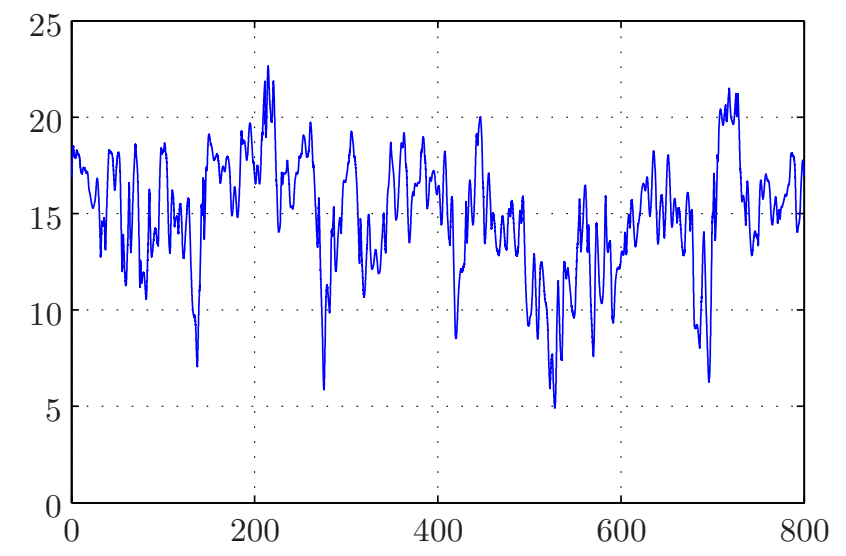

Fig. 8: Blade-pitch reference (degrees)

\section{B. Stochastic Simulations}

In this section simulation results for a stochastic wind speed is presented. Control inputs which are pitch reference $\theta_{i n}$ and generator reaction torque reference $Q_{i n}$ along with system outputs which are rotor rotational speed $\omega_{r}$ and electrical power $P_{e}$ are plotted in figures 8-11. As it could be seen in figure 7 the estimated wind speed is inaccurate and the controller is designed such that it can handle the uncertainties which arise from this inaccuracy. Simulation results show good regulations of generated power and rotational speed, however one can get an even better regulation by making the controllers more aggressive which results in higher fatigue loads on the actuators and the drivetrain.

\section{CONCLUSION}

In this paper we solved the problem of robust control of a wind turbine using $D K$-iteration technique. Parametric uncertainties are considered in the uncertain model and then we have used $\mu$-synthesis toolbox to design a set of controllers. Estimated wind speed is used to calculate control signal from outputs of controllers. The final controller is implemented on a FAST simulation model with 10 degrees of freedom and simulation with stochastic wind speed based on IEC standard is done. The results show good regulation 


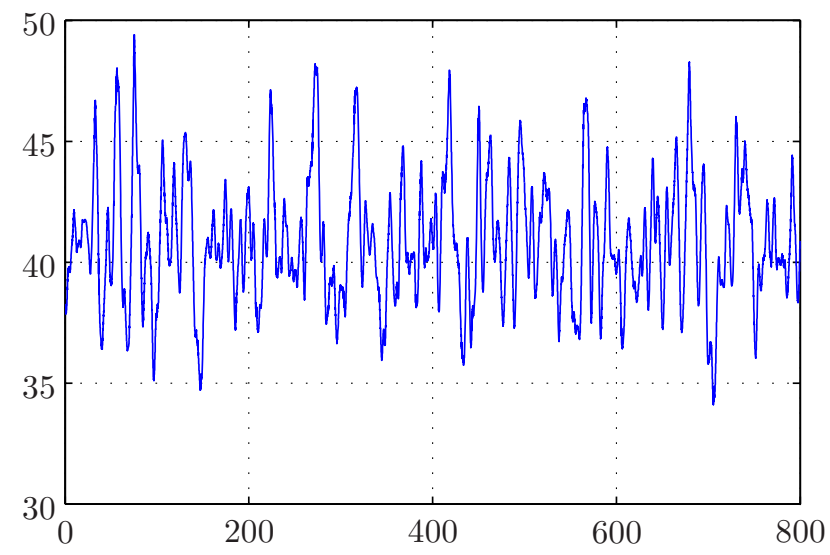

Fig. 9: Generator-torque reference (kilo N.M.)

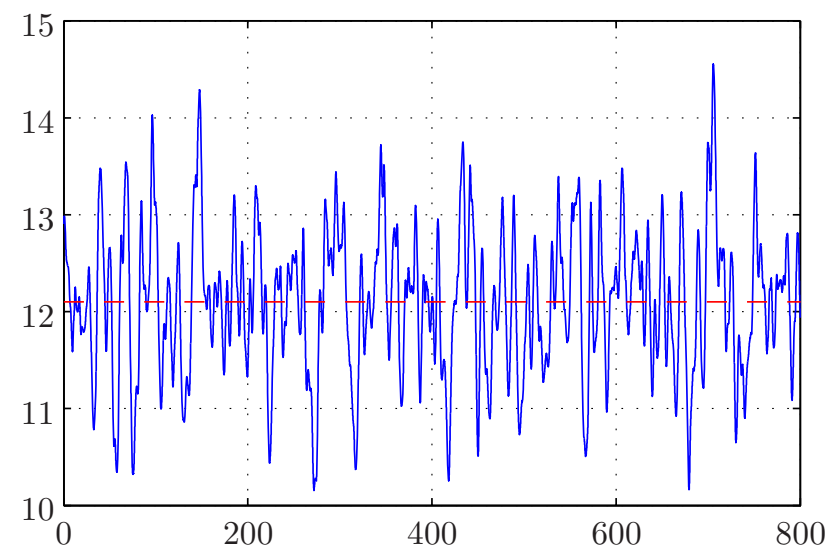

Fig. 10: Rotor rotational speed $\left(\omega_{r}\right)(\mathrm{rpm})$

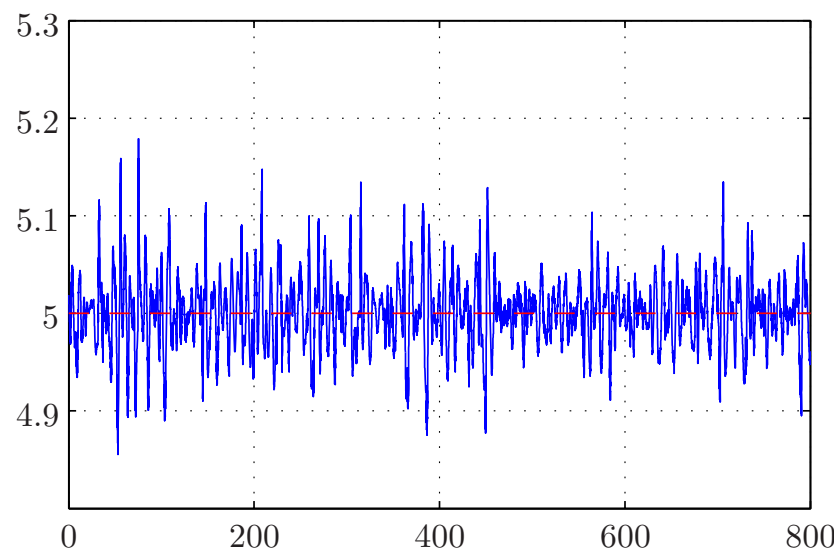

Fig. 11: Electrical power (mega watts)

of generated power and rotational speed for a big range of wind speed changes.

\section{ACKNOWLEDGMENTS}

The first author would like to thank Lars Christian Henriksen and Sven Creutz Thomsen for their valuable comments.

\section{REFERENCES}

[1] W.E. Leithead and Bill Connor. Control of variable speed wind turbines: Design task. Int J Control, 73(13):1189-1212, 2000.

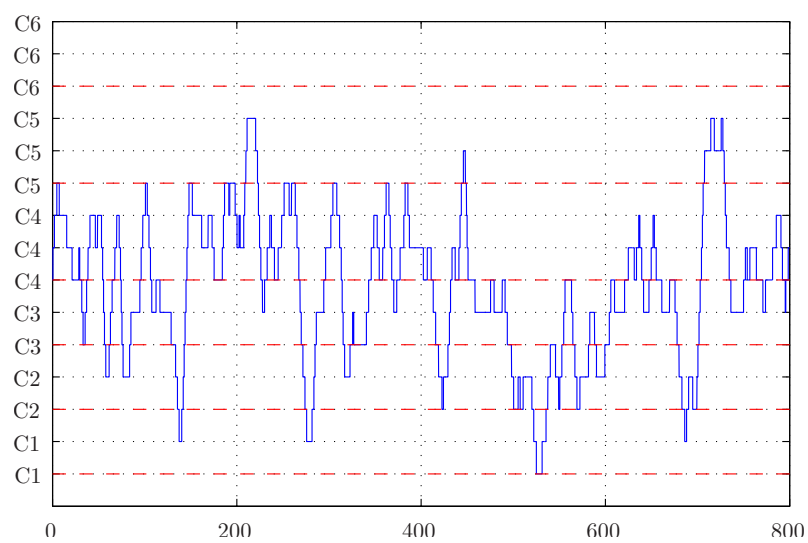

Fig. 12: Controller selection sequence

[2] J.H. Laks, L.Y. Pao, and A.D. Wright. Control of wind turbines: Past, present, and future. Proceedings of the American Control Conference, pages 2096-2103, 2009.

[3] Fernando D. Bianchi, Hernan De Battista, and Ricardo J. Mantz. Wind Turbine Control Systems: Principles, Modelling and Gain Scheduling Design. Springer, 2006.

[4] Johnson and Fingersh. Adaptive pitch control of variable-speed wind turbines. J. Sol. Energy Eng. (USA), 130(3):031012-1-7, 2008.

[5] M. Geyler and P. Caselitz. Robust multivariable pitch control design for load reduction on large wind turbines. Journal of Solar Energy Engineering, 130, 2008.

[6] Sven Creutz Thomsen. Nonlinear control of a wind turbine. Master's thesis, Technical University of Denmark, Informatics and Mathematical Modelling, Lyngby, Denmark, 2006.

[7] Kasper Zinck Østergaard. Robust, Gain-Scheduled Control of Wind Turbines. PhD thesis, Automation and Control Department of Electronic Systems, Aalborg University, Aaloborg, Denmark, 2008.

[8] Lars Christian Henriksen. Model predictive control of a wind turbine. Master's thesis, Technical University of Denmark, Informatics and Mathematical Modelling, Lyngby, Denmark, 2007.

[9] Mahmood Mirzaei, Hans Henrik Niemann, and Niels Kjlstad Poulsen. Dk-iteration robust control design of a wind turbine. In IEEE MultiConference on Systems and Control, Denver, Colorado, 2011.

[10] M. Harris, M. Hand, and A. Wright. Lidar for turbine control. Technical report, National Renewable Energy Laboratory, Golden, CO, 2006.

[11] Peter Bjørn Andersen. Advanced Load Alleviation for Wind Turbines using Adaptive Trailing Edge Flaps: Sensoring and Control. $\mathrm{PhD}$ thesis, Technical University of Denmark, Denmark, 2010.

[12] Sigurd Skogestad and Ian Postlethwaite. Multivariable Feedback Control Analysis and design. John Wiley \& Sons, Second Edition, 2005.

[13] Allan Juul Larsen and Thomas Stampe Mogensen. Individuel pitchregulering af vindmølle. Master's thesis, Technical University of Denmark, Informatics and Mathematical Modelling, Lyngby, Denmark, 2006

[14] Martin O. L. Hansen. Aerodynamics of Wind Turbines. Earthscan, 2008

[15] J. Jonkman, S. Butterfield, W. Musial, and G. Scott. Definition of a 5MW reference wind turbine for offshore system development. Technical report, National Renewable Energy Laboratory, Golden, CO, 2009.

[16] Jason M. Jonkman and Marshall L. Buhl Jr. Fast users guide. Technical Report NREL/EL-500-38230, National Renewable Energy Laboratory, Golden, CO, August 2005.

[17] Gary J. Balas, John C. Doyle, Keith Glover, Andy Packard, and Roy Smith. Robust Control Toolbox. The MathWorks, Inc., June 2001.

[18] The MathWorks, Inc. M-Analysis and Synthesis Toolbox, June 1998. 